\title{
Escoamento superficial em Latossolo Amarelo distrófico típico sob diferentes agroecossistemas no nordeste paraense
}

\author{
Cristiane F. G. da Costa', Ricardo de O. Figueiredo ${ }^{2}$, \\ Francisco de A. Oliveira ${ }^{3}$ \& Izabela P. de O. Santos ${ }^{4}$
}

\begin{abstract}
RESUMO
Na bacia dos igarapés Timboteua e Buiuna, no Estado do Pará, avaliou-se a influência das mudanças de uso da terra e do manejo do solo sobre as taxas de escoamento superficial. Foram estabelecidas 18 parcelas experimentais $\left(1 \mathrm{~m}^{2}\right)$ sendo três em cada um dos seis agroecossistemas avaliados, a saber: i) Capoeira de 20 anos (CP); ii) Sistema agroflorestal / derruba-e-queima (SQ); iii) Sistema agroflorestal / corte-e-trituração (ST); iv) Cultivo de mandioca / corte-e-trituração - Roça (RT); v) Cultivo de mandioca / derruba-e-queima - Roça (RQ); vi) Pastagem / derruba-e-queima (PQ). Adicionalmente foram instalados, na mesma localidade, dois pluviômetros e três coletores de água de chuva $(\mathrm{CH})$ para monitoramento da precipitação. $\mathrm{Em} 26$ datas ao longo da estação chuvosa de 2010, foram coletadas 234 amostras, obtendo-se alta correlação entre volumes precipitado e escoado. O agroecossistema de Pastagem (PQ) degradada apresentou o maior valor de $54,53 \%$ do total de escoamento superficial medido nesta pesquisa, e o SAF, que estava em recuperação de 7 anos após uma queima, o menor valor de $1,11 \%$. O escoamento superficial decresceu dos agroecossistemas de menor para os sistemas de maior percentagem de material orgânico.
\end{abstract}

Palavras-chave: derruba-e-queima, corte-e-trituração, uso da terra, fluxos hídricos, Amazônia oriental

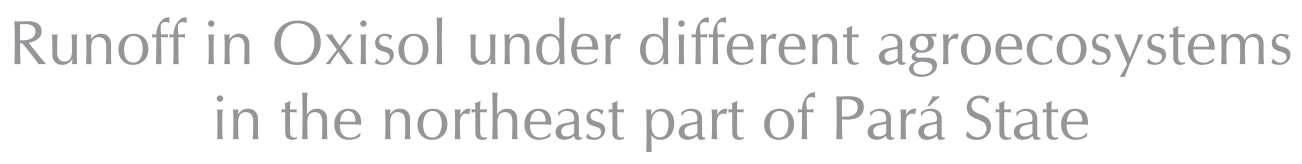

\begin{abstract}
In the watershed of the Timboteua and Buiuna streams in the State of Pará, the effect of land use change and soil management on the runoff rates was evaluated. Eighteen experimental plots $\left(1 \mathrm{~m}^{2}\right)$ were established, three in each one of the six evaluated agroecosystems as follows: i) 20 years Secondary vegetation ("Capoeira") (CP), ii) Agroforestry system / slash-and-burn (SQ), iii) Agroforestry system / chop-and-mulch (ST), iv) Cassava crop / chop-and-mulch (RT), v) Cassava crop / slash-and-burn (RQ), vi) Cattle pasture / slash-and-burn (PQ). Nearby these plots two rain gauges and three rainwater collectors for monitoring of precipitation were also installed. Along 2010 rainy season 234 samples were collected on 26 different dates. A strong correlation was found between precipitation and runoff, being the highest value of $54.53 \%$ of total volume of superficial flow for Cattle pasture degraded and lowest of $1.11 \%$ for Agroforestry system that was under recovery for 7 years after burning. The runoff decreased in agroecosystems with lower percentage of organic material in relation to systems with higher percentage.
\end{abstract}

Key words: slash-and-burning, chop-and-mulching, agroecosystems, water fluxes, Eastern Amazon

\footnotetext{
${ }^{1}$ Embrapa Amazônia Oriental, Tv. Dr. Enéas Pinheiro, s/n, CEP 66095-100, Belém, PA. Fone: (91) 3266-2100. E-mail: cristianeformigosa@yahoo.com.br ${ }^{2}$ Embrapa Meio Ambiente, Rodovia SP 340, Km 127,5, CEP 13820-000, Jaguariúna, SP. Fone: (19) 3311-2771. E-mail: ricardo.figueiredo@embrapa.br ${ }^{3}$ UFRA, Tv. Dr. Enéas Pinheiro, s/n, CEP 66077-530, Belem, PA. Fone: (91) 3210-5186. E-mail: francisco.oliveira@ufra.edu.br

${ }^{4}$ UEPA, Tv. Dr. Enéas Pinheiro, s/n, CEP 66095-100, Belém, PA. Fone: (91) 3204-1147. Email: izabela.santos04@gmail.com
} 


\section{INTRODUÇÃO}

A água possui importantes funções ecossistêmicas e, uma vez alterada em sua quantidade e qualidade em função do tipo de uso da terra, compromete a disponibilidade dos recursos hídricos visando ao atendimento da demanda da sociedade. Estudos dos efeitos de alteração de ecossistemas amazônicos sobre as propriedades hídricas do solo (Cogo et al., 2003) e o ciclo hidrológico em microbacias, têm demonstrado que a remoção da floresta prejudica a capacidade de infiltração e de armazenamento de água no solo, na zona das raízes, além de diminuir a interceptação e a evapotranspiração. Como resultado disto, o escoamento superficial tende a aumentar ocasionando incrementos no deflúvio e escoamento de base (Jipp et al., 1998).

No nordeste do estado do Pará, localizado na Amazônia oriental, as atividades agropecuárias, além de se expandirem em áreas anteriormente florestadas, têm ocupado zonas ripárias, resultando em redução da qualidade da água em microbacias hidrográficas (Lima et al., 2007). Desta maneira, a adoção de boas práticas de manejo do solo, associada ao uso sustentável dos recursos hídricos, torna-se essencial para a recuperação ambiental das áreas alteradas.

Portanto, estudos que relacionem o uso da terra com a qualidade dos recursos hídricos são necessários para validação de práticas conservacionistas do solo. Desta forma objetivou-se avaliar, neste trabalho de pesquisa, a influência de diferentes agroecossistemas e de manejo do solo (corte-e-trituração e derruba-e-queima) sobre as perdas de água por escoamento superficial em uma bacia de drenagem, no nordeste paraense.

\section{Material e Métodos}

$\mathrm{O}$ experimento foi instalado em duas propriedades de pequenos agricultores, localizadas na Comunidade São João, situada a $01^{\circ} 00^{\prime} 41,4^{\prime \prime}$ S e $47^{\circ} 38^{\prime} 38,7^{\prime}$ ' W, na bacia de drenagem dos igarapés contíguos Timboteua e Buiuna, contribuinte da Bacia do Rio Marapanim. A área da bacia estudada é de aproximadamente de 8.756 ha (Figura 1) e se localiza em dois municípios do nordeste do Estado do Pará: Marapanim e Igarapé-Açu.

O solo da área experimental é o Latossolo Amarelo distrófico típico textura média. O clima é do tipo Am e do subtipo climático Am2 (Köppen) com temperatura média anual em torno de $26,5^{\circ} \mathrm{C}$. A média anual de precipitação pluviométrica está em torno de $2500-3000 \mathrm{~mm}$ e de umidade relativa do ar entre $80-85 \%$ (Pachêco \& Bastos, 2006).

$\mathrm{O}$ ecossistema terrestre original da região em que a bacia está inserida é do tipo Floresta Equatorial Subperenifólia e Hidrófila. Atualmente, observa-se predomínio de ecossistemas florestais em vários estágios sucessionais, onde as terras sob uso agrícola estão em pousio.

Quanto ao uso da terra, a bacia dos igarapés contíguos Timboteua e Buiuna apresenta as seguintes classes (área drenada e seu percentual em relação à área da bacia) visualizadas na Tabela 1.

As avaliações ocorreram em duas propriedades agrícolas familiares nas quais foram alocadas três parcelas experimentais

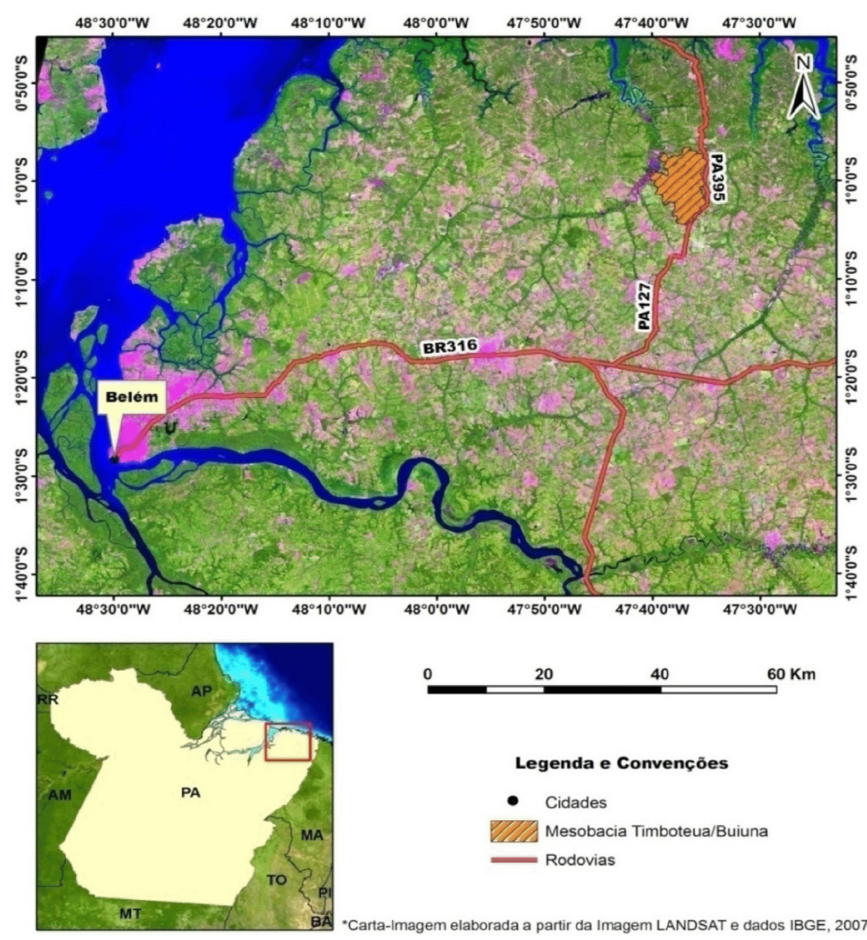

Figura 1. Bacia de drenagem dos igarapés contíguos Timboteua e Buiuna, onde se situa a área experimental na comunidade São João, nordeste do Estado do Pará, Marapanim (PA) Brasil

Tabela 1. Quantificação de áreas definidas para as classes de uso e cobertura da terra na bacia dos igarapés contíguos Timboteua e Buiuna, nordeste paraense

\begin{tabular}{lrr}
\hline \multicolumn{1}{c}{ Unidade de mapeamento } & \multicolumn{2}{c}{ Área } \\
\cline { 2 - 3 } & \multicolumn{1}{c}{ ha } & \multicolumn{1}{c}{$\%$} \\
Floresta antropizada & 605 & 6,90 \\
Ecossistema sucessional maduro - "capoeira alta" & 1.803 & 20,60 \\
Ecossistema sucessional intermediário - "capoeira baixa" & 3.302 & 37,80 \\
Campos aluviais & 192 & 2,20 \\
Agroecossistema de pastagem não manejado - "pasto sujo" & 1.358 & 15,50 \\
Agroecossistema de pastagem - "pasto limpo" & 1.259 & 14,40 \\
Agroecossistemas - "cultivos agrícolas" & 41 & 0,47 \\
Formação de agroecossistemas - "solo sob preparo" & 136 & 1,60 \\
\hline
\end{tabular}

para amostragem do escoamento superficial no solo em cada um dos seis diferentes agroecossistemas (tratamentos) nas mesmas condições biofísicas de solo e clima. Todas as parcelas foram implantadas em áreas com declividade aproximada de $5 \%$ e representativa percentagem de cobertura do solo e vegetação de cada agroecossistema. A água de chuva foi amostrada utilizando-se três coletores, que serviram como referência em relação à chuva de cada período amostrado. $\mathrm{O}$ delineamento experimental utilizado foi inteiramente casualizado, com sete tratamentos, sendo uma testemunha e três repetições, totalizando 21 parcelas experimentais. Foram instalados, adicionalmente, dois pluviômetros para registro do volume de chuva ocorrido nos períodos amostrados.

Em 26 datas diferentes foram coletadas, no período de janeiro a junho de 2010 (estação chuvosa) 234 amostras de água de chuva e de escoamento superficial. Nessas campanhas de campo foi avaliado o escoamento acumulado ao longo de períodos constituídos por diferentes números de 
dias. A razão disto decorre da necessidade de um volume mínimo de $60 \mathrm{~mL}$ de escoamento superficial para possibilitar as medições in situ e as análises laboratoriais realizadas em pesquisa parceira.

Desta forma, durante a época chuvosa do ano de 2010, o escoamento superficial foi monitorado nos seguintes agroecossistemas: i) Capoeira de 20 anos (CP); ii) Sistema agroflorestal (SAF) com preparo de área por derruba-equeima (SQ); iii) Sistema agroflorestal (SAF) com preparo de área por corte-e-trituração (ST); iv) Cultivo de mandioca com preparo de área por corte-e-trituração (RT); v) Cultivo de mandioca - com preparo de área por derruba-e-queima (RQ) e vi) Pastagem com preparo de área por derruba-e-queima (PQ). A descrição detalhada de cada agroecossistema (localização, dimensão, preparo de área, histórico de manejo e outras características) é apresentada na Tabela 2.

Com vista à avaliação do escoamento superficial foram instaladas, em cada agroecossistema, parcelas de 1 x 1 (1 $\mathrm{m}^{2}$ ). Cada uma dessas parcelas possuía três de suas laterais delimitadas por tábuas de madeira $(100 \times 30 \mathrm{~cm})$ enterradas no solo até a profundidade de $10 \mathrm{~cm}$ enquanto na lateral receptora da água escoada foi colocada uma calha de polietileno de alta densidade (HDPE; $\varnothing=50 \mathrm{~mm}$ ) medindo um metro de comprimento e conectada a uma mangueira de silicone $(\varnothing=$ $20 \mathrm{~mm}$ ) para condução da água escoada até um recipiente de polipropileno $(20 \mathrm{~L})$ alocado em um pequeno buraco fora da parcela. Trata-se de um método adotado por Silva et al. (2005) e Moraes et al. (2006).

Para cálculo de densidade realizou-se a coleta de três amostras de solo nas profundidades de 0-0,05 e 0,05-0,10 m em cada parcela monitorada. Os equipamentos utilizados foram anel volumétrico de Kopeck; estufa de $105^{\circ} \mathrm{C}$ e balança de precisão. A densidade do solo foi determinada de acordo com EMBRAPA (1997).

Os coletores de água de chuva $(\mathrm{CH})$ foram instalados na mesma localidade, a $01^{\circ} 00^{\prime} 25,61^{\prime \prime} \mathrm{S}$ e $47^{\circ} 38^{\prime} 03,31^{\prime \prime} \mathrm{W}$, em área aberta, ou seja, local sem influência na interceptação da precipitação. Cada coletor se constituiu de um funil de polipropileno $(\varnothing=103,2 \mathrm{~mm}$ ) instalado a $1,5 \mathrm{~m}$ acima do solo, com sua abertura superior recoberta com tela de nylon ( malha $=0,5 \mathrm{~mm}$ ) e conectado por uma mangueira de silicone inerte $(\varnothing=20 \mathrm{~mm})$ até um recipiente de polipropileno $(5 \mathrm{~L})$ descritos na Figura 2. Para o registro do volume precipitado dois pluviômetros foram instalados segundo a padronização da

Tabela 2. Localização, dimensão, preparo de área, histórico de manejo e características dos seis diferentes agroecossistemas avaliados neste estudo

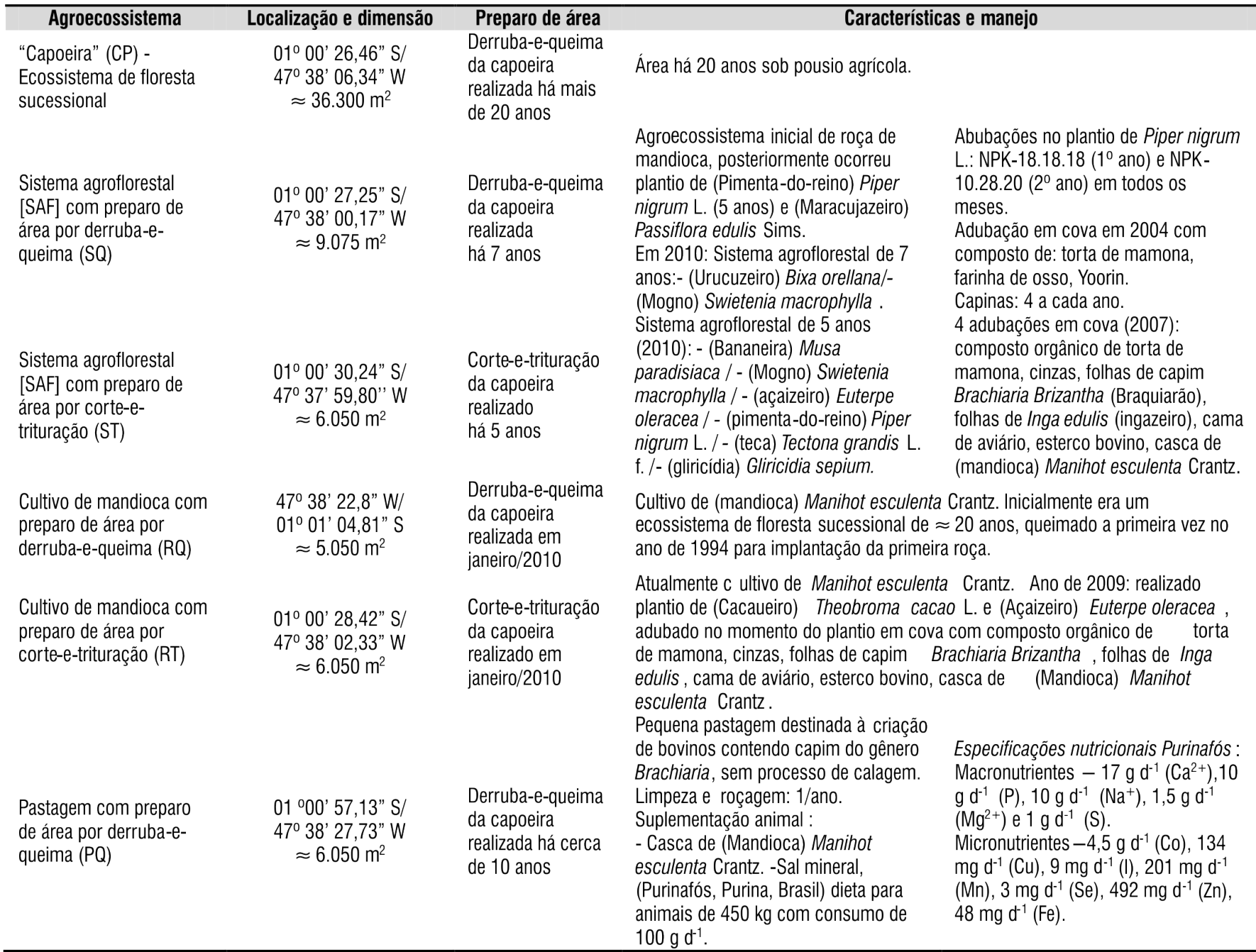




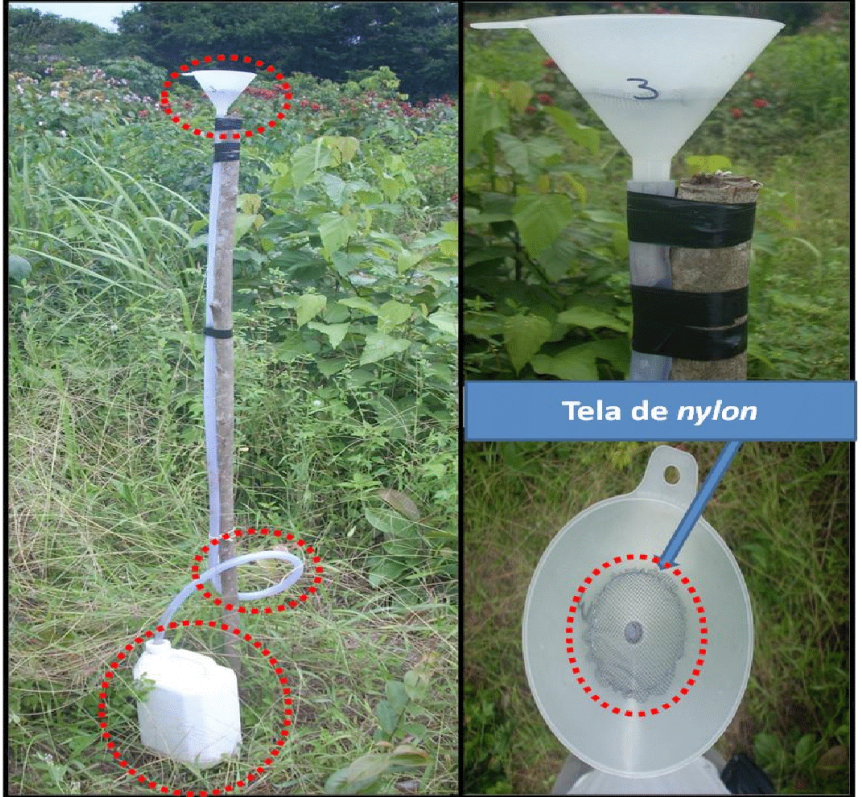

Figura 2. Coletor de água da chuva com destaque para cada um dos componentes de sua constituição

ANEEL - Agência Nacional de Energia Elétrica e o INMET Instituto Nacional de Meteorologia (DNAEE, 1970).

Os dados foram analisados quanto à natureza da distribuição (paramétrica ou não-paramétrica) a partir de teste de normalidade de Kolmogorov-Smirnov e Shapiro-Wilk e de homogeneidade, através do teste de variância de Levene. Após esta análise preliminar dos resultados foram feitos a análise descritiva, a análise de correlação de Spearman $(\mathrm{p}<0,05 ; 0,01)$ e o teste de significância de Tukey $(\mathrm{p}<0,05)$ e Kruskal-Wallis $(\mathrm{p}<0,05)$.

\section{Resultados E Discussão}

Ao longo do período estudado (Jan-Jun/2010) o total precipitado na área experimental foi de 1.276,80 $\mathrm{mm}$ (Figura 3). O maior índice pluviométrico mensal ocorreu em junho (324,6 $\mathrm{mm}$ ) seguido de março $(306,4 \mathrm{~mm})$.

O total médio precipitado nos seis primeiros meses do ano no período de 1995 a 2010, foi de 1.963,1 mm (Cordeiro et al., 2010). Desta forma, a precipitação ocorrida no período do presente estudo foi atipicamente inferior.

De fato, de acordo com os boletins de análises e previsões climáticas da RPCH (2010a, 2010b, 2010c) nos meses de janeiro, fevereiro, março, abril, maio e junho, ocorreu irregularidade na distribuição sazonal das chuvas, com pontos isolados de padrão acima ou abaixo do normal.

Nos registros da RPCH observa-se que no primeiro trimestre predominaram áreas com precipitação abaixo do normal no setor oeste, Calha Norte, região do Marajó e nordeste paraense, influenciadas pela alteração na circulação produzida essencialmente pelo fenômeno El Niño porém no mês de março houve enfraquecimento das anomalias positivas (águas mais quentes que o normal) de TSM (Temperatura da Superfície do Mar) no Pacífico equatorial, caracterizando o declínio do fenômeno El Niño (RPCH, 2010a, 2010b) o que pode explicar

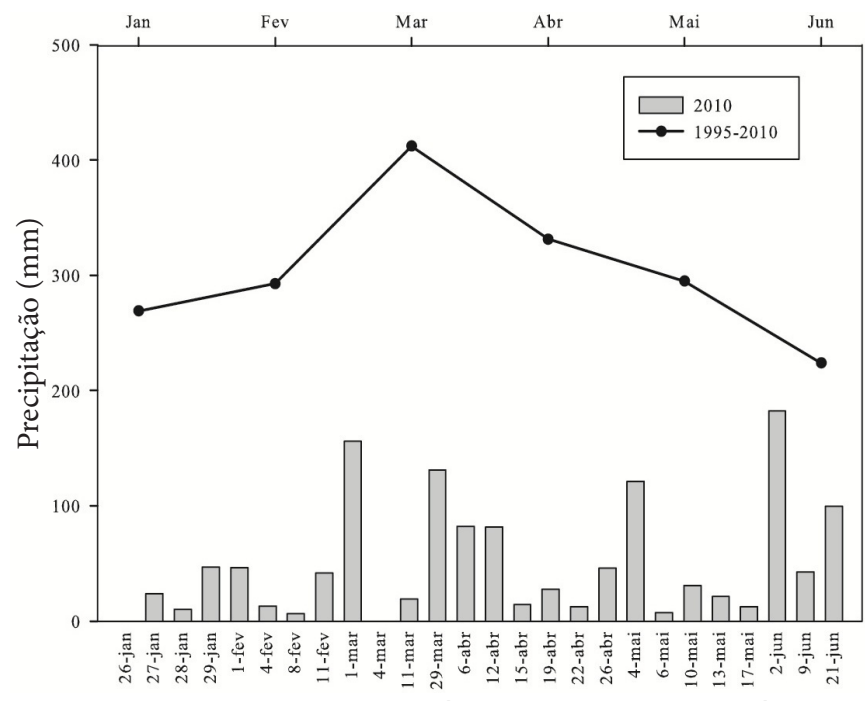

Figura 3. Precipitação pluviométrica mensal no período de 1995 a 2010 e precipitação pluviométrica acumulada $(\mathrm{mm})$ nas datas de amostragem de escoamento superficial (janeiro a junho de 2010) na área experimental, Comunidade de São João, Marapanim, PA

os valores mais elevados de precipitação acumulada observados em março, na área experimental.

Desta forma, a precipitação abaixo do normal afetou a amostragem do escoamento superficial pois não foi possível fazer coletas diárias em virtude da baixa ocorrência de eventos de chuva intensa, típico na região, ao longo da estação chuvosa.

Os dados de escoamento superficial apresentaram forte assimetria, segundo o coeficiente de Pearson, ou seja, muita diferença entre os valores das medidas de posição, média e mediana. Referidos valores refletem ausência de normalidade na distribuição dos dados e variância não homogênea dos dados de escoamento nas parcelas experimentais, nos diferentes agroecossistemas (Tabela 3).

Observou-se diferença significativa do escoamento superficial entre pelo menos um dos agroecossistemas avaliados, segundo o teste de Kruskal-Wallis $(\mathrm{p}<0,05)$ ocorrendo maior média de $1,93 \mathrm{~mm}$ no agroecossistema de Pastagem (PQ) e valor mínimo de $0,06 \mathrm{~mm}$ no agroecossistema de SAF-derruba e queima (SQ) representando $1,11 \%$ do total de escoamento superficial ao longo do experimento. As maiores somas totais de lâmina escoada ocorreram nos agroecossistemas PQ $(34,79$ $\mathrm{mm})$ e SAF - corte-e-trituração (ST) $(15,25 \mathrm{~mm})$ (Tabela 3$)$.

SQ foi diferente estatisticamente do agroecossistema de Pastagem (PQ), do Cultivo de mandioca/a/corte-e-trituraçãoRoça (RT) e do SAF-corte-e-trituração (ST) (Tabela 3). Ressaltase que todos os agroecossistemas tiveram a particularidade de serem áreas inicialmente exploradas pela agricultura convencional (Tabela 2) e, por problemas de produtividade, o produtor resolveu testar, de forma estratégica, algumas prováveis formas de plantio e manejos de preparo do solo para recuperação de áreas, como é o caso dos SAF's avaliados. Em tempos distintos foram aplicados dois arranjos e manejos diferentes nessas áreas.

Infere-se, portanto, que houve influência das características e atributos físico-hídricos, como a densidade do solo dos diferentes agroecossistemas sobre a lâmina escoada (Figura 4). 
Tabela 3. Estatística descritiva para os valores de lâmina de escoamento superficial $(\mathrm{mm})$ nas parcelas dos diferentes agroecossistemas avaliados ao longo do período de 26-jan a 21-jun de 2010

\begin{tabular}{|c|c|c|c|c|c|c|c|c|}
\hline $\begin{array}{c}\text { Tratamentos/ } \\
\text { Agroecossistemas }\end{array}$ & Média & Mediana & Erro padrão & Soma & Assimetria & Curtose & Mínimo & Máximo \\
\hline Capoeira (CP) & 0,31 & $0,22 \mathrm{ba}$ & 0,07 & 5,82 & 1,68 & 2,02 & 0,02 & 1,09 \\
\hline Pastagem (PQ) & 1,93 & $0,68 \mathrm{~b}$ & 0,59 & 34,79 & 1,53 & 1,84 & 0,02 & 8,69 \\
\hline $\begin{array}{l}\text { Cultivo de mandioca/ } \\
\text { derruba-e-queima-Roça } \\
\text { (RQ) } \\
\text { Cultivo de mandioca/a/ }\end{array}$ & 0,18 & $0,10 \mathrm{ba}$ & 0,04 & 2,85 & 1,35 & 0,76 & 0,03 & 0,57 \\
\hline $\begin{array}{l}\text { corte-e-trituração-Roça } \\
\text { (RT) }\end{array}$ & 0,36 & $0,28 \mathrm{~b}$ & 0,10 & 4,38 & 2,19 & 5,42 & 0,07 & 1,30 \\
\hline $\begin{array}{l}\text { SAF - derruba-e-queima } \\
\text { (SQ) }\end{array}$ & 0,06 & $0,04 \mathrm{a}$ & 0,02 & 0,71 & 1,62 & 1,61 & 0,02 & 0,21 \\
\hline $\begin{array}{l}\text { SAF - corte-e-trituração } \\
\text { (ST) }\end{array}$ & 0,70 & $0,35 \mathrm{~b}$ & 0,19 & 15,25 & 2,05 & 3,89 & 0,04 & 3,32 \\
\hline
\end{tabular}

* Medidas estatísticas de posição e dispersão

* Dados não normais; foram desconsiderados os valores de variância e desvio padrão e considerados os valores de erro padrão

* Medianas seguidas da mesma letra minúscula na coluna não diferem significativamente entre si pelo teste de Kruskal-Wallis $(p<0,05)$

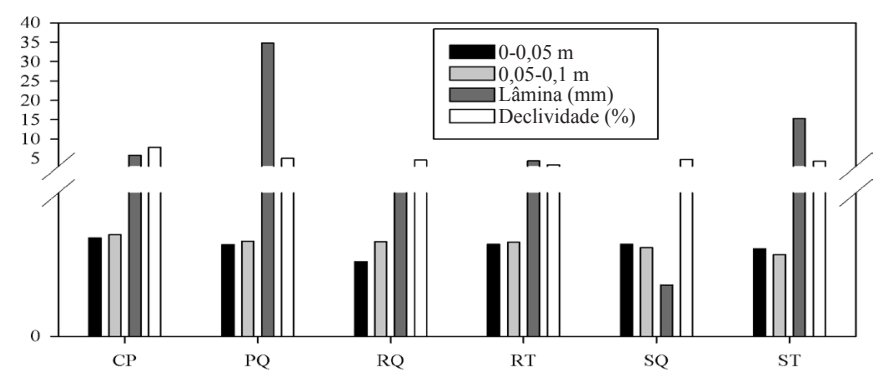

Figura 4. Médias de densidade do solo $\left(\mathrm{Mg} \mathrm{m}^{-3}\right)$ em duas profundidades $(0-0,05 \mathrm{~m} ; 0,05-0,10 \mathrm{~m})$, lâmina total escoada $(\mathrm{mm})$ nos ecossistemas em 26 eventos de coleta e declividade $(\%)$

A densidade do solo depende do peso, da forma e distribuição do tamanho e arranjo das partículas; valores acima de $1,6 \mathrm{Mg} \mathrm{m}^{-3}$ são prejudiciais ao crescimento das raízes das plantas. O manejo inadequado que afete a densidade do solo reflete em alteração dos atributos físico-hídricos do solo, o que aumenta a susceptibilidade do solo ao escoamento superficial e, concomitantemente, a erosão hídrica (Canillas \& Salokhe, 2002). Constatou-se diferença estatística para os valores de densidade do solo em um dos tratamentos $(\mathrm{p}<0,05)$ - Cultivo de mandioca/derruba-e-queima-Roça (RQ) (Tabela 4).

Tabela 4. Densidade do solo $\left(\mathrm{Mg} \mathrm{m}^{-3}\right)$ e declividade (\%) nos diferentes agroecossistemas

\begin{tabular}{|c|c|c|c|}
\hline \multirow{2}{*}{ Agroecossistemas } & \multicolumn{2}{|c|}{ Densidade do solo } & \multirow{2}{*}{$\begin{array}{c}\text { Declividade } \\
\text { (\%) }^{(2)}\end{array}$} \\
\hline & $0-0,05 \mathrm{~m}^{(1)}$ & $0,05-0,10 \mathrm{~m}^{(1)}$ & \\
\hline (CP) Capoeira & $1,37 \mathrm{~b}$ & 1,41 & 7,9 \\
\hline (PQ) Pastagem & $1,28 b$ & 1,32 & 5,0 \\
\hline $\begin{array}{l}\text { (RQ) Cultivo de mandioca/ derruba-e- } \\
\text { queima-Roça }\end{array}$ & $1,04 \mathrm{a}$ & 1,32 & 4,6 \\
\hline $\begin{array}{l}\text { (RT) Cultivo de mandioca/a/corte-e- } \\
\text { Trituração-Roça }\end{array}$ & $1,28 b$ & 1,31 & 3,3 \\
\hline (SQ) SAF - derruba-e-queima & $1,29 \mathrm{~b}$ & 1,23 & 4,8 \\
\hline (ST) SAF - corte-e-trituração & $1,22 \mathrm{ba}$ & 1,14 & 4,3 \\
\hline Desvio padrão & 0,19 & 0,19 & \\
\hline Erro padrão & 0,03 & 0,03 & \\
\hline
\end{tabular}

(1) Medida estatística de posição, média. $\mathrm{N}=9$

(2) Declividade média $=5 \%$

* 0 perfil 0,05-0,10 m teve dados não normais, razão pela qual foram considerados os valores de erro padrão ao invés do desvio padrão. $\mathrm{N}=54$

* No perfil 0-0,05 m médias seguidas da mesma letra minúscula na coluna não diferem significativamente entre si pelo teste de Tukey para amostras independentes CV $=13,04 \%(p<0,05)$
Relacionando os valores de lâmina escoada nas parcelas e densidade do solo, verificou-se que no agroecossistema de Cultivo de mandioca/derruba-e-queima-Roça (RQ) ocorreu a menor densidade no perfil de $0-0,05 \mathrm{~m}\left(1,04 \mathrm{Mg} \mathrm{m}^{-3}\right)$ e baixa lâmina total escoada $(2,85 \mathrm{~mm})$. Tal ocorrência pode ser explicada por uma infiltração maior de água no solo nesse agroecossistema e, consequentemente, menor escoamento superficial.

As áreas de Cultivo de mandioca/derruba-e-queima-Roça (RQ) e o Cultivo de mandioca/a/corte-e-trituração-Roça (RT) apresentavam um histórico inicial de uso parecido, diferenciandose nos estágios de pousio. No momento da execução do preparo de áreas, o RQ passava pelo seu segundo ano de pousio e o RT estava há seis meses de pousio. Tal particularidade não foi tão sensível ao escoamento superficial devido, provavelmente, à interferência de outros fatores ambientais e históricos de uso da terra porém é possível notar, nos valores de densidade do solo para o perfil superficial, à possível relação da prática do descanso do solo.

Apesar de não se explicar a relação entre atributos fisicohídricos do solo, somente por uma única variável é notável, neste caso, a correlação positiva dessas variáveis $(\rho=0,26)$. $\mathrm{O}$ agroecossistema RQ foi submetido, durante alguns anos, a manejo não mecanizado, com queima da vegetação e estágios de pousio (Tabela 2). De acordo com Souza et al. (2004) solos sem mecanização apresentam melhores condições de qualidade e menores alterações nos atributos físicos do solo, pois oferece melhor quantidade, continuidade espacial e tamanho dos poros, que são alguns dos fatores responsáveis pela infiltração de água no solo.

Entretanto, apesar do preparo de área através da derrubae-queima ser bastante praticado pela agricultura familiar na região estudada, dado ao seu baixo custo e a curto prazo quando adotado pousio relativamente longo, propiciar efêmeros benefícios pelo aporte de nutrientes presentes nas cinzas (Schmitz, 2007), este apresenta muitas desvantagens, quando comparado com a prática do corte-e-trituração. Essas desvantagens ocorrem ainda tanto em termos produtivos quanto ambientais.

Segundo Kanashiro \& Denich (1998) após vários ciclos de derruba-e-queima na mesma área, os níveis de sustentabilidade 
decrescem por perda de fertilidade do solo e infestação de plantas espontâneas (ervas daninhas). O efeito negativo da queima na sustentabilidade de agroecossistemas foi observado também por Matos et al. (2012) e Sommer et al. (2004).

Sommer (2001) afirma a necessidade de se evitar a queima no manejo de cultivos agrícolas no nordeste paraense. Em um cultivo no qual se adota o ciclo de corte de sete anos de pousio com dois cortes, o balanço de nutrientes sob a prática de derruba-e-queima, foi negativo para os principais nutrientes ocorrendo valores muito elevados de exportação de fósforo de $\approx 11 \mathrm{~kg} \mathrm{ha}^{-1}$ (63\% do estoque) justificando um desequilíbrio para o fosfato, nutriente limitante ao crescimento das culturas na região.

Os agroecossistemas de pastagem (PQ), Cultivo de mandioca/a/corte-e-trituração-roça (RT) e SAF-derruba-equeima (SQ) mostraram, mesmo apresentando valores muito próximos de densidade, uma grande variação na lâmina total escoada confirmando a influência das características biofísicas e o histórico de uso da terra de cada sistema estudado; tais valores foram confirmados pelo teste estatístico (Tabela 3).

A classe de uso da terra de Pastagem representa 29,9\% da área total da bacia avaliada. Portanto, o agroecossistema de Pastagem (PQ) que contabilizou 54,53\% do total de escoamento superficial medido nesta pesquisa, deve ter uma participação muito importante no escoamento superficial da bacia estudada.

Sarmento et al. (2010) avaliaram pastagens de rebanho na agricultura familiar do nordeste paraense e identificaram o padrão de início de pecuarização baseado no processo sucessivo de derruba-e-queima da capoeira. De acordo com o autor, tais agricultores praticam, em sua maioria, o manejo de pastejo rotacional e contínuo, com lotações animais muito acima da capacidade de suporte das pastagens, ocasionando superpastejo.

O agroecossistema PQ, por sua vez, apresenta microrrelevo (trilhas), solo desprotegido e um manejo bem precário, com visível degradação. Tais fatos podem ter favorecido um escoamento superficial maior devido à baixa capacidade de infiltração do solo, ocasionada por fatores degradantes, como pressão de pastoreio elevada. Além disto, a menor taxa de infiltração no solo degradado se deve ao processo de degradação da estrutura do solo aliado à ausência de cobertura morta no solo (Alves et al., 2007).

O microrrelevo superficial encontrado na área de estudo é influenciado pelo preparo do solo, que afeta o volume de poros da camada preparada e, juntamente com a cobertura vegetal, determina o escoamento superficial, a infiltração de água no solo e outras variáveis físico-hídricas (Darboux \& Huang, 2005). A aplicação de técnicas de formação e de manutenção da cobertura vegetal, assim como o manejo de pastagens (especialmente o controle da pressão de pastejo e sistema de pastejo) é essencial para mitigar impactos de deterioração desses sistemas.

A ocorrência de um escoamento superficial elevado indica possibilidade de degradação da pastagem, decorrente de um manejo inadequado. O resultado encontrado no agroecossistema de Pastagem também foi observado por Bertol et al. (2011) que, avaliando erosão hídrica em pastagens de campo nativo manejadas com queima e sem queima, identificaram uma perda total elevada de água, na forma de escoamento superficial nos dois tratamentos; no entanto, dentro de uma proporção o campo nativo queimado apresentou volume de enxurrada $120 \%$ superior ao sem queima. A diminuição da cobertura do solo devido à queima da vegetação ocasionou aumento de $49 \%$ na taxa máxima de enxurrada em relação à ausência de queima a qual aumentou de 39 para $58 \mathrm{~mm} \mathrm{~h}^{-1}$.

As parcelas foram alocadas em áreas com declividade quase semelhante, sendo um pouco maior na Capoeira (CP) por não ter sido encontrada na área declividade menor (Tabela 4) porém tal diferença não afetou a coleta dos dados pois, mesmo com uma declividade maior, o que teoricamente poderia induzir a uma coleta maior, o CP apresentou baixo valor de soma total $(5,82 \mathrm{~mm})$ representando $9,12 \%$ da lâmina total de escoamento superficial na área experimental (Tabela 3) ou seja, o escoamento superficial é afetado por diversos fatores agroclimáticos e biofísicos da paisagem; no caso do CP é visível a influência direta da interceptação do dossel florestal.

O percentual de cobertura morta no solo pode ter influenciado no escoamento de água nas parcelas, porque nos agroecossistemas em que a quantidade de cobertura morta do solo era visivelmente maior, como na capoeira (CP), Cultivo de mandioca/corte-e-trituração-roça (RT) e SAF-derruba-e-queima (SQ), a lâmina escoada foi menor. Cardoso et al. (2004) também encontraram a mesma relação.

Desta forma, o SQ com preparo de área realizado há sete anos, apresentava mais cobertura morta no solo que o SAFcorte-e-trituração (ST). Isto pode ter direcionado os valores inferiores de lâmina escoada no SQ em virtude, provavelmente, de uma infiltração maior. Alves et al. (2007) encontraram, estudando densidade do solo e infiltração de água como indicadores da qualidade física de um Latossolo Vermelho distrófico em recuperação, altos valores de infiltração em área com cobertura morta no solo. Segundo os autores isso deve ter ocorrido em razão da influência da matéria orgânica sobre as propriedades físicas do solo.

A lâmina total de escoamento em ST, o qual foi submetido a corte e trituração há 5 anos, representa $23,9 \%$ do total do escoamento coletado em todos os agroecossistemas avaliados.

Infere-se que este valor pode ter ocorrido pelo fato de ST apresentar uma disposição de árvores com espaçamento visivelmente maior e um conteúdo menor de cobertura morta no solo, facilitando o fluxo de água diferentemente de SQ, diferença esta confirmada pelo teste estatístico (Tabela 3). Segundo McDowell et al. (2001) a capacidade de infiltração da água da chuva seria menor quanto menor fosse o percentual de cobertura morta no solo. Quanto maior a percentagem de material orgânico no solo, a rugosidade da superfície do solo e a evapotranspiração da cultura, maiores são as taxas de infiltração de água no solo quando ocorrer uma chuva e, consequentemente, menores são as perdas por escoamento superficial.

Santos et al. (2007) encontraram, em uma análise da perda de água e solo em diferentes coberturas vegetais no semiárido da Paraíba, maiores valores de escoamento e, em consequência, a maior relação com a precipitação média anual, 35,2 e 38,0\% em parcelas desmatadas. No mesmo estudo foi testada uma parcela com vegetação rasteira e cobertura morta e posteriormente avaliada a retirada dessa vegetação, resultando em um 
aumento gradual do escoamento superficial. Tal fato aponta para o importante papel que a vegetação e a cobertura morta desempenham no controle das perdas de água por escoamento superficial sobremaneira quando ocorre irregularidade temporal e espacial das chuvas.

Vários outros autores comprovaram a eficácia da cobertura morta no solo na redução do efeito da erosão hídrica provocado pelo escoamento superficial (Bertol, 1994; Beutler et al., 2003).

Observou-se, no presente experimento, forte relação entre lâmina precipitada e lâmina escoada, demonstrando associação e interdependência dessas variáveis com coeficiente de correlação positivo $(\rho=0,815)$ e significativo a nível de $1 \%$ (Figura 5).

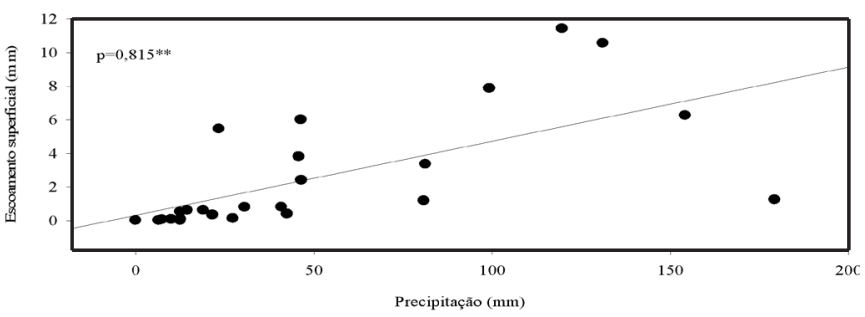

Figura 5. Correlação da precipitação pluviométrica acumulada e média da lâmina total de escoamento superficial $(\mathrm{N}=26)$

Na Figura 6 visualiza-se que a lâmina de escoamento variou bastante entre os agroecossistemas estudados devido, possivelmente, à influência das características biofísicas da paisagem e do manejo de cada agroecossistema. Como discutido acima, o escoamento superficial não pode ser explicado apenas pela influência de uma única variável.

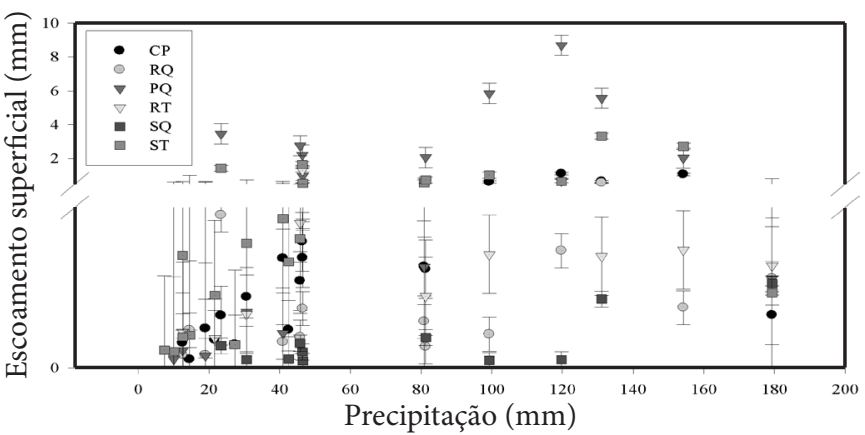

Figura 6. Precipitação pluviométrica acumulada e lâmina escoada nos diferentes ecossistemas (média e erro padrão; $\mathrm{N}=26$ )

Alencar et al. (2006) observaram que o estudo do escoamento superficial está relacionado ao conhecimento dos fatores que potencializam as relações hídricas de uma bacia hidrográfica. Sabe-se que os principais fatores que contribuem para o aumento do escoamento superficial, são os agroclimáticos e fisiográficos como: quantidade, intensidade, duração e distribuição da precipitação, interceptação da cobertura vegetal, demanda atmosférica, impermeabilização do solo, desflorestamento, movimentação de terra, ocupação inadequada do solo e declividade.

O escoamento superficial dentro das parcelas avaliadas decresceu dos agroecossistemas de menor para os sistemas de maior percentagem de material orgânico. Confirma-se, portanto, que as características de uso e manejo do solo influenciaram nas lâminas escoadas nas parcelas (Figura 6). Moraes et al. (2006) concluíram, analisando o escoamento superficial no solo de uma área de floresta e pastagem na Amazônia oriental, que o escoamento superficial teve resposta diferente nos dois sistemas pois a precipitação com intensidade média estimada na floresta raramente ultrapassou a capacidade de infiltração, diferentemente do agroecossistema de pastagem. Na pastagem, ao contrário, cerca de $75 \%$ da taxa de precipitação com intensidade média ultrapassaram a capacidade de infiltração próximo à superfície, provocando escoamento superficial muito maior do que na floresta.

O escoamento nas parcelas do presente estudo foi relativamente pequeno sugerindo boa taxa de infiltração e baixa ou quase desprezível contribuição do escoamento superficial para formação de enxurrada que, junto com o escoamento de base, compõe os rios e reservatórios. Wickel et al. (2007) verificaram, estudando a geração de enxurrada em duas bacias de cabeceira na mesma região aqui avaliada, que a taxa de precipitação máxima observada durante o período de estudo de $52,3 \mathrm{~mm} \mathrm{~h}^{-1}$ nunca ultrapassou as taxas de infiltração final, em qualquer um dos pontos avaliados. Este resultado foi semelhante aos resultados encontrados em outros estudos feitos em latossolos amarelos na Amazônia central.

\section{Conclusões}

1. Os diferentes tipos de agroecossistema e manejo (cortee-trituração; e derruba-e-queima) influenciaram na variação do escoamento superficial permitindo o uso dessa variável físico-hídrica, juntamente com o monitoramento de outras variáveis secundárias, para caracterizações e avaliação de áreas degradadas.

2. Ocorreu eficiência perceptível da cobertura morta no solo haja vista que nas áreas com maior porcentagem de cobertura morta houve menor escoamento superficial, com destaque para o sistema de plantio em SAF-derruba-e-queima (inicial) área em recuperação, que indicou o menor valor de escoamento superficial.

3. A pastagem degradada com utilização da queima e não manejada, apresentou o maior escoamento superficial, sendo um sistema de manejo não indicado em termos de sustentabilidade.

\section{Agradecimentos}

Os autores agradecem: ao técnico Reginaldo Frazão, pelo apoio no trabalho de campo, e à equipe do Laboratório de Sensoriamento Remoto, pelo processamento de imagens (Embrapa Amazônia Oriental); à EMBRAPA Amazônia Oriental, ao $\mathrm{CNPq}$ pelo apoio financeiro a esta pesquisa e à CAPES, pela concessão da bolsa de estudo; aos projetos GESTABACIAS (EMBRAPA - Macroprograma 2, Código: 02.07.06.017) e "Agricultura familiar e qualidade de água no Nordeste Paraense: Conservação de serviços agroecossistêmicos em escala de bacia hidrográfica" (CNPQ - CT-HIDRO, Código: 574.648/2008-9). 


\section{Literatura Citada}

Alencar, D. B. S.; Silva, C. L.; Oliveira, C. A. S. Influência da precipitação no escoamento superficial em uma microbacia hidrográfica do Distrito Federal. Revista Brasileira de Engenharia Agrícola e Ambiental, v.26, p.103-112, 2006.

Alves, M. C.; Suzuki, L. G. A. S.; Suzuki, L. A. S. Densidade do solo e infiltração de água como indicadores da qualidade física de um latossolo vermelho distrófico em recuperação. Revista Brasileira de Ciência do Solo, v.31, p.617-625, 2007.

Bertol, I. Erosão hídrica em Cambissolo Húmico distrófico sob diferentes preparos do solo e rotação de culturas. Revista Brasileira de Ciências do Solo, v.18, p.267-271, 1994.

Bertol, I.; Gobbi, E.; Barbosa, F. T.; Paz-Ferreiro, J.; Gebler, L.; Ramos, J. C.; Werner, R. de S. Erosão hídrica em campo nativo sob diversos Manejos: perdas de água e solo e de fósforo, potássio e amônio na água de enxurrada. Revista Brasileira de Ciências Solo, v.35, p.1421-1430, 2011.

Beutler, J. F.; Bertol, I.; Veiga, M.; L.; Wildner, P. Perdas de solo e água num latossolo vermelho aluminoférrico submetido a diferentes sistemas de preparo e cultivo sob chuva natural. Revista Brasileira de Ciências do Solo, v. 27, p.509-517, 2003.

Cardoso, D. P.; Silva, M. L. N.; Curi, N.; Sáfadi, T.; Fonseca, S.; Ferreira, M. M.; Martins, S. G.; Marques, J.J.G.S.M. Erosão hídrica avaliada pela alteração na superfície do solo em sistemas florestais. Scientia Forestalis, v.66, p.25-37, 2004.

Canillas, E. C.; Salokhe, V. M. A decision support system for compaction assessment in agricultural soils. Soil Tillage Research, v.65, p.221-230, 2002.

Cogo, N. P.; Levien, R.; Schwarz, R.A. Perdas de solo e água por erosão hídrica influenciadas por métodos de preparo, classes de declive e níveis de fertilidade do solo. Revista Brasileira de Ciências do Solo, v.27, p.743-753, 2003.

Cordeiro, A. H. F.; Pachêco, N. A.; Santiago, A. V. Climatologia da precipitação no município de Igarapé-Açu, PA. Período: 1995-2009. In: Congresso Brasileiro de Meteorologia, 16, 2010, Belém. Anais... Belém: SBMET, 2010. CD-Rom

Darboux, F.; Huang, C. Does soil surface roughness increase or decrease water and particle transfers? Soil Science Society of America Journal, v.69, p.748-756, 2005.

DNAEE - Departamento Nacional de Águas e Energia Elétrica. Normas e Recomendações Hidrológicas. Anexo I - Pluviometria. Brasília: DNAEE, 1970. 94p.

EMBRAPA - Empresa Brasileira de Pesquisa Agropecuária. Manual de métodos de análise de solo. 2.ed. Rio de Janeiro: EMBRAPA, 1997. 212p.

Jipp, P. H.; Nepstad, D. C.; Cassel, D. K.; Carvalho, C. R. Deep soil moisture storage and transpiration in forests and pastures of seasonally-dry Amazonia. Climatic Change, v.39, p.395-412, 1998.

Kanashiro, M.; Denich, M. Possibilidades de utilização e manejo adequado de áreas alteradas e abandonadas na Amazônia brasileira. Brasília: MCT/CNPq, 1998. 157p.

Lima, L. M.; Souza, E. L.; Figueiredo, R. O. Retenção do dimetoato e sua relação com $\mathrm{pH}$ e teores de argila e matéria orgânica nos sedimentos da zona não saturada de uma microbacia no nordeste paraense. Acta Amazonica, v.37, p.187-194, 2007.
Matos, F. O.; Castro, R. M. da S.; Ruivo, M. de L. P.; Moura, Q. L. de M. Teores de nutrientes do solo sob sistema agroflorestal manejado com e sem queima no estado do Pará. Floresta e Ambiente, v.19, p.257-266, 2012.

McDowell, R. W.; Sharpley , A.N.; Condron, L.M.; Haygarth , P.M.; Brookes, P.C. Processes controlling soil phosphorus release to runoff and implications for agricultural management. Nutrient Cycling in Agroecosystems, v.59, p.269-284, 2001.

Moraes, J. M.; Schuler, A. E.; Dunne, T.; Figueiredo, R. O.; Victoria, R. L. Water storage and runoff processes in plinthic soils under forest and pasture in Eastern Amazonia. Hydrological Processes, v.20, p.2509-2526, 2006.

Pachêco, N. A.; Bastos, T. X. Boletim agrometeorológico 2004 Igarapé- Açu, PA. (Embrapa Amazônia Oriental. Documentos, 216). Belém: Embrapa Amazônia Oriental, 2006. 28p.

RPCH - Rede Estadual de Previsão Climática e Hidrometeorológica do Pará. Boletim de Análise e Previsão Climática de Fevereiro, v.4, p.1-3, 2010a.

RPCH - Rede Estadual de Previsão Climática e Hidrometeorológica do Pará. Boletim de Análise e Previsão Climática de Abril, v.4, p.1-3, 2010 b.

RPCH - Rede Estadual de Previsão Climática e Hidrometeorológica do Pará. Boletim de Análise e Previsão Climática de Julho, v.4, p.1-3, 2010.c

Santos, C. A. G.; Silva, R. M.; Srinivasan, V. S. Análise das perdas de água e solo em diferentes coberturas superficiais no semiárido da Paraíba. Revista Okara: Geografia em Debate, v.1, p.1-152, 2007.

Sarmento, C. M. B.; Veiga, J. B.; Rischkowsky, B., Kato, O. R.; Siegmund-Schultze, M. Caracterização e avaliação da pastagem do rebanho de agricultores familiares do nordeste paraense. Acta Amazonica, v.40, p.415-424, 2010.

Schmitz, H. A transição da agricultura itinerante na Amazônia para novos sistemas. Revista Brasileira de Agroecologia, v.2, p.46-49, 2007.

Silva, M. G. M.; Figueiredo, R. O.; Costa, F. F.; Pachêco Júnior, A. de C.; Lima, L. M.; Cunha, E. da S.; Kato, O.R. Transferência de nutrientes e carbono por escoamento superficial para igarapés em áreas agrícolas sob diferentes sistemas de preparo de área para plantio (corte-e-queima e corte-e-trituração) no nordeste paraense. In: Congresso de estudantes e bolsistas do experimento LBA, 2, 2005, Manaus. Anais... Manaus: LBA, 2005. CD Rom.

Sommer, R. No Fires! Slash-and-Mulch - A promising alternative. Zentrum für Entwicklungsforschung news, v.6, p.8, 2001.

Sommer, R.; Vlek, P. L.G.; Sá, T. D. de A.; Vielhauer, K.; Coelho, R. de F. R.; Fölster, H. Nutrient balance of shifting cultivation by burning or mulching in the Eastern Amazon evidence for subsoil nutrient accumulation. Nutrient Cycling in Agroecosystems, v.68, p.257-271, 2004.

Souza, Z.M.; Leite, J. A.; Beutler, A. N. Comportamento de atributos físicos de um Latossolo Amarelo sob agroecossistemas do Amazonas. Revista Brasileira de Engenharia Agrícola e Ambiental, v.24, p.654-662, 2004.

Wickel, A. J.; Giesen, N. C.; Sá, T. de A. Stormflow generation in two headwater catchments in eastern Amazonia, Brazil. Hydrological Processes, v.22, p.3285-3293, 2007. 